\title{
Occurrence and Origins of Thiols in Deep Strata Crude Oils
}

\author{
MENG WANG ${ }^{1}$, GUANGYOU ZHU ${ }^{2}$
}

${ }^{1}$ Research Institute of Petroleum Exploration and Development, PetroChina, Beijing 100083, China, wangmeng85@petrochina.com.cn

${ }^{2}$ Research Institute of Petroleum Exploration and

Development, PetroChina, Beijing 100083, China,

zhuguangyou@petrochina.com.cn

Thiols (or mercaptans) in crude oils have been considered to be associated with thermochemical sulfate reduction (TSR). However, the molecular composition and the formation mechanism of thiols in crude oils are not clear. This study provides the molecular composition of thiols in several deep strata condensate oils (condensates) from the Tarim Basin. Selective Michael addition products of thiols were characterized using Fourier transform ion cyclotron resonance mass spectrometry (FT-ICR MS) and comprehensive two-dimensional gas chromatography - mass spectrometry ( $\mathrm{GC} \times \mathrm{GC} \mathrm{MS})$. The carbon numbers and double bond equivalents of the thiols ranged between 4-20 and 0-10, respectively. Abundant diamondoidthiols found in two condensates were from high-temperature reservoirs. Various thiol compounds with multiple heteroatoms $\left(\mathrm{S}_{2}, \mathrm{~S}_{3}, \mathrm{~S}_{1} \mathrm{O}_{1}\right.$, $\mathrm{S}_{1} \mathrm{O}_{2}$ and $\mathrm{S}_{2} \mathrm{O}_{1}$ class species) were detected in two other condensates, and low reservoir temperature made it possible to prevent the depletion of the multiple-heteroatom thiols. The pronounced ${ }^{34} \mathrm{~S}$ enrichment in $\mathrm{H}_{2} \mathrm{~S}$ and high-abundance thiadiamondoids indicates that four condensates were originally sourced from Cambrian strata and suffered severe TSR alteration. The pathway of thiols formation was speculated as: TSR-generated $\mathrm{H}_{2} \mathrm{~S}$ reacts with petroleum hydrocarbons. Deep Cambrian strata in the Tarim Basin has the potential of being a huge hydrocarbon resource, although the high maturity and TSR alteration may negatively impact the quantity and quality of reserves and lead to a high $\mathrm{H}_{2} \mathrm{~S}$ content. The results presented here provide new insights into the TSR reaction, which may assist deep oil exploration and facilitate evaluation of the extent of TSR alteration. 